\title{
Genetic parameters of rumination time and feed efficiency traits in primiparous Holstein cows under research and commercial conditions
}

\author{
M. V. Byskov, ${ }^{* 1}$ A. Fogh, ${ }^{*}$ and P. Løvendahl† \\ *Dairy \& Beef Research Centre, SEGES, Skejby, DK 8800 Aarhus N, Denmark \\ †Department of Molecular Biology and Genetics, Aarhus University, AU-Foulum, DK 8830 Tjele, Denmark
}

\section{ABSTRACT}

Feed efficiency has the potential to be improved both through feeding, management, and breeding. Including feed efficiency in a selection index is limited by the fact that dry matter intake (DMI) recording is only feasible under research facilities, resulting in small data sets and, consequently, uncertain genetic parameter estimates. As a result, the need to record DMI indicator traits on a larger scale exists. Rumination time (RT), which is already recorded in commercial dairy herds by a sensorbased system, has been suggested as a potential DMI indicator. However, RT can only be a DMI indicator if it is heritable, correlates with DMI, and if the genetic parameters of $\mathrm{RT}$ in commercial herd settings are similar to those in research facilities. Therefore, the objective of our study was to estimate genetic parameters for RT and the related traits of DMI in primiparous Holstein cows, and to compare genetic parameters of rumination data between a research herd and 72 commercial herds. The estimated heritability values were all moderate for DMI (0.32-0.49), residual feed intake (0.23-0.36), energy-corrected milk (ECM) yield (0.49-0.70), and RT (0.14-0.44) found in the research herd. The estimated heritability values for ECM were lower for the commercial herds (0.08-0.35) than that for the research herd. The estimated heritability values for RT were similar for the 2 herd types (0.28-0.32). For the research herd, we found negative individual level correlations between RT and DMI ( -0.24 to -0.09$)$ and between RT and RFI ( -0.34 to -0.03$)$, and we found both positive and negative correlations between RT and ECM $(-0.08$ to 0.09). For the commercial herds, genetic correlations between RT and ECM were both positive and negative $(-0.27$ to 0.10$)$. In conclusion, RT was not found to be a suitable indicator trait for feed intake and only a weak indicator of feed efficiency.

Key words: genetics, rumination time, feed efficiency

Received December 23, 2016.

Accepted August 4, 2017.

${ }^{1}$ Corresponding author: mvl@seges.dk
INTRODUCTION

Feed costs comprise over half of the operating costs of European dairy herds (European commission 2015). Thus, achieving high feed efficiency of dairy cows is essential to increasing the profitability of milk production (VandeHaar 1998; Veerkamp, 1998). Feed efficiency can be improved through optimization of feeding and management (Kristensen et al., 2015). Additionally, feed efficiency has been shown to vary with respect to genetic background, which implies that genetic selection may be a used to improve feed efficiency (Williams et al., 2011; Tempelman et al., 2015).

Feed efficiency is increasingly expressed as residual feed intake (RFI), defined as observed DMI minus predicted DMI based on milk production, BW, and BW change. Thereby, feed efficiency is expressed as metabolic efficiency, independent of production level and size (Connor et al., 2013). Thus, to include RFI in a breeding selection index, phenotypic information on individual DMI is required. However, as individual DMI recording is only performed in research facilities, including DMI in the selection index is challenged by the shortage of phenotypic data (Berry, et al., 2014; Manzanilla Pech et al., 2014; Tetens et al., 2014). Alternatively, traits that are already being recorded in largescale commercial dairy herds might serve as correlated indicator traits for DMI. Rumination time (RT) may be such a trait. On-farm automatic recording of RT is enabled by sensor-based systems that record rumination activity sounds produced by jaw or by ear movements (Schirmann et al., 2009; Braun et al., 2013; Bikker et al., 2014). The observation that rumination activity is stimulated by fiber intake (Mertens, 1997; Nørgaard et al., 2010) suggests that RT might constitute a DMI indicator if DMI and RT have a robust genetic correlation.

To enable DMI to be predicted based on RT in commercial herds, data quality and genetic parameters found under practical conditions must resemble the data quality and genetic parameters found in research facilities. Neither the genetic parameters of RT nor 
the potential of using RT as an indicator trait of DMI have been compared between research facilities and commercial herds. The objectives of our study were 2 -fold. First, we sought to identify genetic parameters for RT and the related traits of DMI, RFI, and milk production at early, peak, mid, and late lactation periods in primiparous Holstein cows. Second, we examined whether genetic parameters of rumination are similar between commercial herds and research facilities.

\section{MATERIALS AND METHODS}

\section{Animals and Facilities}

Research Herd. Research facility data were collected from Danish Holstein cows housed in a freestall barn with cubicles and slatted floor and milked in an automatic milking system (AMS; DeLaval, Tumba, Sweden) allowing free cow traffic at the Danish Cattle Research Centre (Foulum, Denmark). The cows had ad libitum access to TMR varying in nutritional content in accordance with the particular trial in which the cows were involved. Data were collected during various trial periods and cows were not nested within trial. The nutritional value of the TMR were all within the recommended requirements, formulated to support the milk yield level of the herd, and allocated in amounts allowing approximately $10 \%$ orts to ensure ad libitum intake. In addition, cows were supplemented with a maximum of $3 \mathrm{~kg}$ of daily concentrate to ensure voluntary access to the AMS. Feed intake data from this study were used previously by Li et al. (2016).

Commercial Herds. Commercial herd data were obtained from registrations for Holstein cows housed in freestall barns and milked in an AMS (Lely, Maassluis, the Netherlands). Cows were fed partially mixed rations and supplemented with concentrates in the AMS during milking.

\section{Data Recording}

Research Herd. Individual feed intake was recorded by feed bins (Insentec, Marknesse, the Netherlands) allowing access via feed gates controlled by neck collars. The feed bins registered the amount of feed leaving the feed bin during the time between each cow's bin entry and exit. Feed intake per visit values were summed into daily feed intake values, from which daily DMI values were calculated with the DM content of the feed offered to each individual cow. Dry matter content of each TMR and concentrate was analyzed within each trial. Milk yield per visit in the AMS was recorded at each milking and condensed into daily milk yield with a moving average approach. Milk composition was assayed for at least two 24-h periods per week and used for estimation of ECM yield. Daily DMI, milk production, and BW data were recorded from January 2003 to April 2015. Rumination time was recorded from May 2013 to May 2016 by a microphone-based rumination monitoring sensor (RuminAct by SCR Engineers Ltd., Netanya, Israel) placed on the left side of each cow's neck. The sensor identifies RT by the sound of regurgitation of feed boluses and by the specific, regular sound pattern related to rumination behavior. Rumination time was recorded in 2-h intervals and daily RT was estimated by accumulation of the 12 2-h intervals within each day. The recordings on DMI, RT, and milk yield were summarized as weekly averages for each individual cow before being subjected to further analysis.

Commercial Herds. Feed intake was not recorded in the commercial dairy herds. However, RT was recorded by the same type of rumination sensor (sold as Qwes HR by Lely) used in the research herd. Cows in the commercial herds were milked in AMS (Lely), and daily milk yields were calculated by the procedure used for the research herd. Milk samples were drawn routinely once every month and analyzed for content of fat and protein. Lactose content was not determined in milk samples from commercial herds.

\section{Data Editing}

Research Herd. Outliers of feed intake were identified as being outside the range of 4 times the residual standard deviation of the regression between intake per visit and visit duration. Outlier detection was performed as 2 runs of this procedure, wherein outliers identified in the first run were omitted for the second run and replaced by predicted values from the regression between intake per visit and visit duration. A DMI data range of 5 to $42 \mathrm{~kg} / \mathrm{d}$ was used. Weekly averages of DMI allowed a maximum of 2 missing records per weekly average. Weekly milk yield averages were required to have at least 2 valid ECM records. Outliers on RT were detected by a filter that sorted out unrealistic RT due to sensor errors or disturbed rumination behavior due to heat. Furthermore, data with missing RT records within $24 \mathrm{~h}$ were eliminated. Data on weekly averages of RT were allowed to have missing daily records due to the limited number of records available. Ultimately, 22,901 DMI and ECM records from 650 cows and 4,045 $\mathrm{RT}$ records from 159 cows were obtained, all 1 to $44 \mathrm{wk}$ after calving.

Commercial Herds. Milk yield data outside 3 times the standard deviation were considered outliers. Rumination time and ECM outliers were determined by the same procedure as in the research herd. Ultimately, 695,516 RT records from 10,475 cows and 28,516 ECM 
records from 8,362 cows were obtained, all 1 to $44 \mathrm{wk}$ after calving.

\section{Data Analysis}

We estimated RFI as the residual error term in the DMI regression using Proc Mixed Procedure in SAS (version 9.2, SAS Institute Inc., Cary, NC) with the following model:

$$
\begin{gathered}
D M I_{i j}=\mu+ \\
W O L_{j}+b_{1} \times M B W_{i}+b_{2} \times B W C_{i} \\
+b_{3} \times E C M_{i}+e_{i j},
\end{gathered}
$$

where $D M I_{i j}$ was the observed DMI $(\mathrm{kg} / \mathrm{d})$ of cow $i$ in week $j, \mu$ is the overall phenotypic mean, $W O L_{j}$ is the fixed effect of week of lactation $j$ (1 to 44 ), $b_{1}$ is the regression coefficient of DMI on metabolic body weight (MBW) measured on cow $i$ in week $j, b_{2}$ is the regression coefficient of DMI on body weight change (BWC) measured on cow $i$ in week $j, \mathrm{~b}_{3}$ is the regression coefficient of DMI on ECM of cow $i$ in week $j$, and $e_{i j}$ is the random residual error term with $\sim \operatorname{IND}\left(0, \sigma_{e}^{2}\right)$, where $\sigma_{e}^{2}$ is the variance of the residual error. Residual feed intake is then the residual $e_{i j}$ from this model. The regression on BW change included both loss and gain situations in a single regression on signed changes, as preliminary findings showed that splitting this into a loss and gain phase was inaccurate especially in early lactation (results not shown; Bingjie Li, AU-Foulum, personal communication).

To explore the potential variations in variance components during lactation, genetic parameters were determined within 4 lactation periods: early (wk 1-4), peak (wk 6-9), mid (wk 18-21), and late (wk 30-33). We determined the genetic parameters by estimating variance and covariance components using the average information residual maximum likelihood (AI-REML) in the DMU package (Madsen and Jensen 2010). Repeatability and heritability estimates were estimated with univariate models, whereas individual level, genetic, and phenotypic correlations were estimated with bivariate models, both using the animal model

$$
y_{i j k l}=\mu+H E_{j}+W O L_{k}+M O R_{l}+p e_{i}+a_{i}+e_{i j k l}
$$

where $y_{i j k l}$ represents the DMI $(\mathrm{kg} / \mathrm{d})$, RFI $(\mathrm{kg} / \mathrm{d})$, ECM $(\mathrm{kg} / \mathrm{d})$, and RT $(\mathrm{min} / \mathrm{d})$ of cow $i ; \mu$ is the overall phenotypic mean of the traits; $H E_{j}$ is the fixed effect of herd $j$ ( 1 for research herd data and 1-72 for commercial herd data); $W O L_{k}$ is the fixed effect of week of lactation $k(1-44) ; M O R_{l}$ is the fixed effect of month of registration $l(1-12) ; p e_{i}$ is the random permanent environmental effect of cow $i$ with $\sim N D\left(0, \mathbf{I} \sigma_{p e}^{2}\right)$, where $\mathbf{I}$ is an identity matrix and $\sigma_{p e}^{2}$ is variance of permanent environment, thereby accounting for repeated recordings for individual cows; $a_{i}$ is the random additive genetic effect of cow $i$ with $\sim N D\left(0, \mathbf{A} \sigma_{a}^{2}\right)$, where $\mathbf{A}$ is an additive genetic relationship matrix and $\sigma_{a}^{2}$ is variance of genetic effects; and $e_{i j k l}$ is the random residual error term with $\sim \operatorname{IND}\left(0, \sigma_{e}^{2}\right)$, where $\sigma_{e}^{2}$ is the variance of the residual error.

Estimate repeatability $(t)$ was estimated from the variance components by the formula $t=\sigma_{\text {cow }}^{2} /$ $\left(\sigma_{\text {cow }}^{2}+\sigma_{e}^{2}\right)$, where $\sigma_{\text {cow }}^{2}$ represents the variance between cow defined by $\sigma_{c o w}^{2}=\sigma_{a}^{2}+\sigma_{p e}^{2}$, and $\sigma_{e}^{2}$ represents the residual error variance. Heritability was estimated as $h^{2}=\sigma_{a}^{2} /\left(\sigma_{p e}^{2}+\sigma_{a}^{2}+\sigma_{e}^{2}\right)$. Due to data shortage, individual level correlations between the traits recorded for the research herd were presented as a proxy for genetic correlations. Individual level correlations were estimated by correlating the random estimates of individual cows. Heritability standard errors and genetic correlations were estimated based on standard errors of variance components determined in DMU software by Taylor series expansions (Madsen and Jensen, 2010).

\section{RESULTS AND DISCUSSION}

\section{Descriptive Results}

Table 1 provides an overview of the descriptive results of the examined traits. The average DMI was 19.5 $\mathrm{kg} / \mathrm{d}$, increasing from $\sim 11 \mathrm{~kg} / \mathrm{d}$ in early lactation to $20 \mathrm{~kg} / \mathrm{d}$ in wk 20 and then remaining steady thereafter throughout the lactation period (Figure 1). The stagnation of DMI in mid and late lactation was expected due to the continuous weight gain and development of the digestion system capacity during the first parity. The results corroborate earlier results by Berry et al. (2014), who found similar patterns of DMI data in lactating primiparous cows. The largest variation in DMI was found in early lactation, in accordance with the findings of Ingvartsen and Friggens (2005) and Karacaören et al. (2006). The average RFI was $0.0 \mathrm{~kg} / \mathrm{d}$ during the total 44 lactation weeks; however, RFI was negative during early, peak, and mid lactation $(-0.1$ to -0.3 $\mathrm{kg} / \mathrm{d})$, and became positive in late lactation $(0.1 \mathrm{~kg} / \mathrm{d})$. Energy-corrected milk yields during the total 44 -wk lactation periods, were similar between the research herd and commercial herds, averaging 29.7 and 29.9 $\mathrm{kg} / \mathrm{d}$ respectively. This also applied to $\mathrm{RT}$, averaging at 413 and $448 \mathrm{~min} / \mathrm{d}$ during the 44 lactation weeks. 
Table 1. Number of records, means, and SD for traits recorded in the research herd and commercial herds

\begin{tabular}{|c|c|c|c|c|c|c|c|}
\hline Parameter & Period & \multicolumn{3}{|c|}{ Research herd } & \multicolumn{3}{|c|}{ Commercial herd } \\
\hline \multirow[t]{4}{*}{ DMI, $\mathrm{kg} / \mathrm{d}$} & Total & 22,901 & 19.5 & 3.1 & & & \\
\hline & Peak & 2,315 & 18.6 & 2.4 & & & \\
\hline & Mid & 2,215 & 20.5 & 2.4 & & & \\
\hline & Late & 2,073 & 20.5 & 2.4 & & & \\
\hline \multirow{3}{*}{ Residual feed intake, $\mathrm{kg} / \mathrm{d}$} & Peak & 1,575 & -0.3 & 2.1 & & & \\
\hline & Mid & 1,523 & -0.1 & 1.7 & & & \\
\hline & Late & 1,432 & 0.1 & 1.8 & & & \\
\hline \multirow[t]{4}{*}{$\mathrm{ECM}, \mathrm{kg} / \mathrm{d}$} & Total & 16,081 & 29.7 & 6.0 & 28,198 & 29.9 & 6.50 \\
\hline & Early & 1,510 & 28.1 & 6.7 & 2,994 & 28.1 & 6.66 \\
\hline & Peak & 1,621 & 31.1 & 6.2 & 2,757 & 31.3 & 5.79 \\
\hline & Mid & 1,567 & 30.4 & 5.5 & 2,581 & 31.1 & 5.43 \\
\hline Rumination time, $\min / \mathrm{d}$ & Late & 385 & 404.5 & 117.8 & 59,662 & 440.4 & 111.6 \\
\hline
\end{tabular}

\section{Repeatability}

Repeatability was estimated for individual animals and residual variance was determined using a repeatability model across 4 phases of lactation, thereby accounting for potential changes during lactation. In general, the examined traits had moderate to high repeatability, indicating a genetic component in the animal variance of the traits. Phenotypic trait data were recorded daily; however, weekly averages of the daily data were analyzed, resulting in a smoothing out of some of the daily variation, and thus perhaps con-

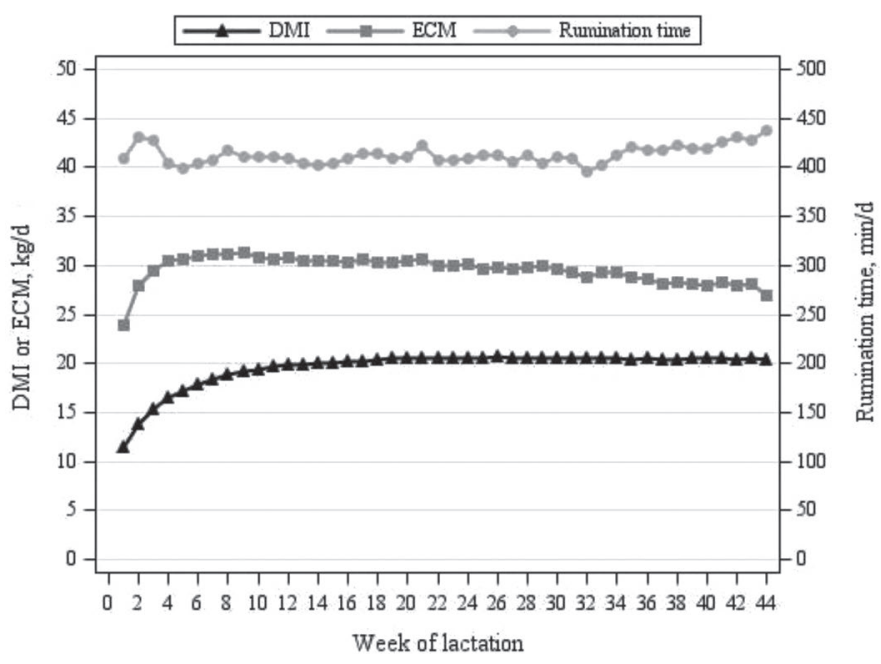

Figure 1. Weekly DMI, ECM yield, and rumination time in primiparous lactating Holstein cows in a research herd. tributing to the relatively high repeatability observed. The repeatability of DMI was estimated to be 0.62 for the total lactation period; this estimate is similar to estimates from research stations in 9 countries (Berry et al., 2014), but lower than the estimate reported by Tetens et al. (2014). The repeatability for DMI estimates increased from 0.75 in early lactation to 0.84 in late lactation, quite similar patterns were found by Tetens et al. (2014), with the exception of low repeatability observation in peak lactation. Repeatability of RFI was 0.46 for the total lactation period; for DMI, repeatability estimates for RFI increased with advancing lactation periods, similar to those reported by Connor et al. (2013) and Tempelman et al. (2015). Repeatability estimates for ECM for both the research herd and commercial herds were similar to our estimates for DMI, and similar to estimates reported by Løvendahl and Chagunda (2011). The repeatability of RT over the total lactation period was 0.75 for the research herd and 0.80 for the commercial herds. As for DMI, repeatability increased with advancing lactation stage. No previous estimates of RT repeatability, with the exception of those described by Byskov et al. (2015), were available.

\section{Heritability}

The heritability of DMI for all cows was moderate at 0.37 for the entire 44 -wk lactation period (Table 2 ). Heritability estimates were higher in mid and late lactation (0.46-0.49) than in early and peak lactation (0.32-0.33). Several studies have found heritability 
Table 2. Repeatability $(\mathrm{t})$, heritability $\left(\mathrm{h}^{2}\right)$, and standard errors of heritability $\left(\mathrm{SE}_{\mathrm{h}}\right)$ for research herd and commercial herds

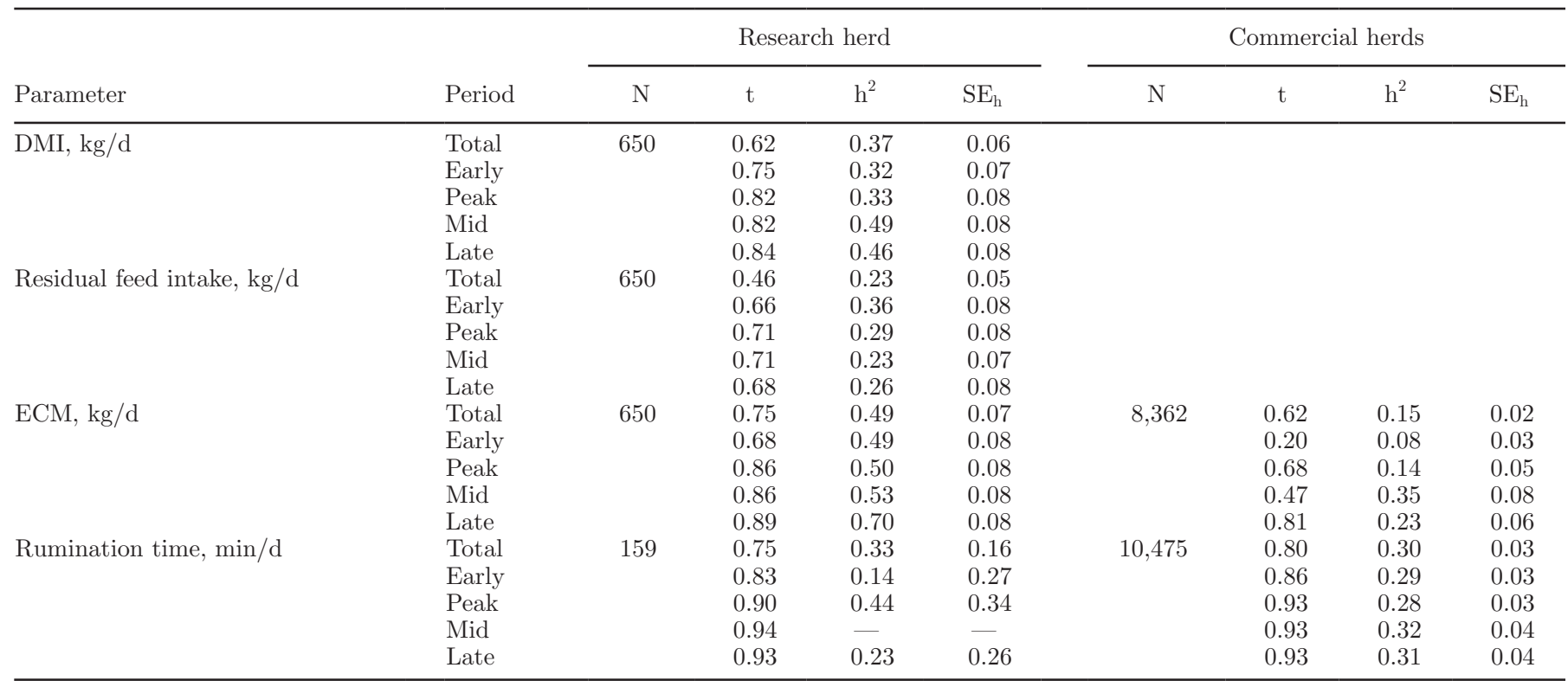

estimates within the same range, with previously reported estimates ranging from 0.12 to 0.52 (Koenen and Veerkamp, 1998; Karacaören et al., 2006; Berry et al., 2007, 2014; Vallimont et al., 2011; Manzanilla Pech et al., 2014; Tetens et al., 2014). In the current study, DMI heritability estimates increased with advancing lactation week. However, considering our data in the context of similar research, there does not seem to be a general pattern in the changes of heritability estimates over lactation stages for DMI (Karacaören et al., 2006; Berry et al., 2007; Liinamo et al., 2012; Manzanilla Pech et al., 2014; Tetens et al., 2014).

Heritability estimates for RFI were somewhat lower than for DMI, with estimates ranging between 0.23 and 0.36 in the different lactation periods and averaging 0.23 for the total lactation period. These estimates resemble the results reported by Connor et al. (2013), but are slightly higher than the values reported by Tempelman et al. (2015). The heritability of RT was also of moderate strength, with estimates for the total lactation period of research and commercial herds being 0.33 and 0.30 , respectively. The heritability based on research herd data (range $=0.14-0.44$ ) was more variable than that based on commercial herd data (range $=$ 0.28-0.32). Due to the limited data set representing the research herd, the standard errors for rumination heritability estimates were large. The heritability estimates for the commercial herds confirm that heritability for RT found in the research herd are reliable. No previous research can support the heritability estimates for RT produced from research herd data.

\section{Individual Level, Phenotypic, and Genetic Correlations}

Individual level, genetic, and phenotypic correlations between RT and DMI, RFI, or ECM are summarized in Table 3. Individual level correlation between random animal estimates for 2 traits expresses the relationship when adjustments are made for all fixed effects; therefore, correlations between animal variance components express, to some extent and only roughly, genetic correlations. Hence, due to the limited data set for the research herd, individual level correlations were chosen to express the potential genetic relationships among traits. The individual level correlation between DMI and RT was -0.22 for the total lactation period, varying between -0.09 and -0.24 for the 4 lactation periods. Phenotypic correlations between the same traits were very close to zero, either positive or negative. No previously reported research can confirm these results, which is presumably due to the shortage of data, as recording of RT previously was performed by chewing halters or by visual detection. These recording methods are laborious and expensive, resulting in small amount of data from few cows. Nonetheless, several studies have focused on the relationship between feed intake and RT. Nørgaard et al. (2010) found that intake of forage NDF was closely related to RT; Mertens (1997) found that daily time spent ruminating was closely related to the intake of physical effective fiber (peNDF), defined by the proportion of fiber retained on a sieve with a pore size of $1.18 \mathrm{~mm}$. This constitutes the proportion of fiber 
that stimulates rumination activity and saliva secretion (Mertens, 1997). Krause et al. (2002) found that feeding animals long-particle alfalfa silage increased daily RT significantly. Adin et al. (2009) found a significantly higher peNDF intake and daily RT with increasing forage content. Likewise, Byskov et al. (2015) observed a positive relationship between forage NDF intake and RT. On the contrary, Yang and Beauchemin (2007) found no effect of feeding 2 levels of forage-to-concentrate ratio and 2 particle lengths of the forage on RT $(\mathrm{min} /$ day) or RT per peNDF intake $(\mathrm{min} / \mathrm{kg})$. These results focus on the relationship between forage NDF intake and RT, as fiber particles stimulate RT. However, keeping feed rations, and thereby forage proportion, constant presumes a close relationship between forage NDF intake and DMI; consequently, it seems reasonable that DMI and RT should be positively correlated. Krause et al. (2002) found that long-particle DMI and RT were positively related. Nonetheless, Schirmann et al. (2012) found no relationship between daily DMI and RT across cows and only a weak negative correlation within cows. Furthermore, even though Clément et al. (2014) found a positive relationship between DMI and $\mathrm{RT}$, the regression estimate they obtained for RT was low $(0.031 \mathrm{~kg} / \mathrm{h})$. The present results support the view that no clear relationship exists between DMI and RT. Consequently, RT does not appear to be a useful indicator trait for DMI in estimation of RFI.

The individual level correlations between RFI and RT produced similar patterns as that for DMI and RT, with a negative correlation in the total lactation period of -0.24 (range $=-0.03$ to -0.34 for different lactation periods). The phenotypic correlations were negative, but close to zero; hence, high feed efficiency and high RT seem to have a weak genetic association. One could speculate that high RT entails a thorough mastication of the feed particles, facilitating further breakdown of the feed, and thereby an increase in the utilization of the feed. This notion is supported by the work of Gregorini et al. (2015), who found that cows selected for high feed efficiency ruminated longer than cows selected for low feed efficiency. In addition, cows selected for high feed efficiency excreted 30\% less large particles in their feces than cows selected for low feed efficiency, which presumably was related to their longer RT and more thorough breakdown of feed particles. Individual level correlations between ECM and RT were very close to zero for the research herd data, with individual level correlations ranging from -0.08 to 0.09 . The same applied to the phenotypic correlations for the research herd, with phenotypic correlations ranging from -0.003 to 0.07 , and for commercial herds, with phenotypic correlations ranging from -0.01 to 0.07 . Genetic correlations between ECM and RT for the commercial herds were close to zero for the total lactation period (0.08), but showed a tendency toward negative genetic correlation in 3 of the 4 lactation periods, with the highest negative genetic correlation being observed in the late lactation period $(-0.27)$. The tendency of negative correlation might be explained by the fact that high peNDF intake stimulated RT (Mertens 1997), which in return may have diluted the energy content of the feed, resulting in suppression of milk production. Notwithstanding, these data had large standard errors, making interpretation of the results difficult.

Estimating heritability across the whole lactation period is helpful for determining when selection for a given trait is most genetically favorable. Nonetheless, it is equally important to know how selection for a given trait in one lactation stage might affect expression of

Table 3. Individual level, phenotypic, and genetic correlation between rumination time and related feed efficiency traits ${ }^{1}$

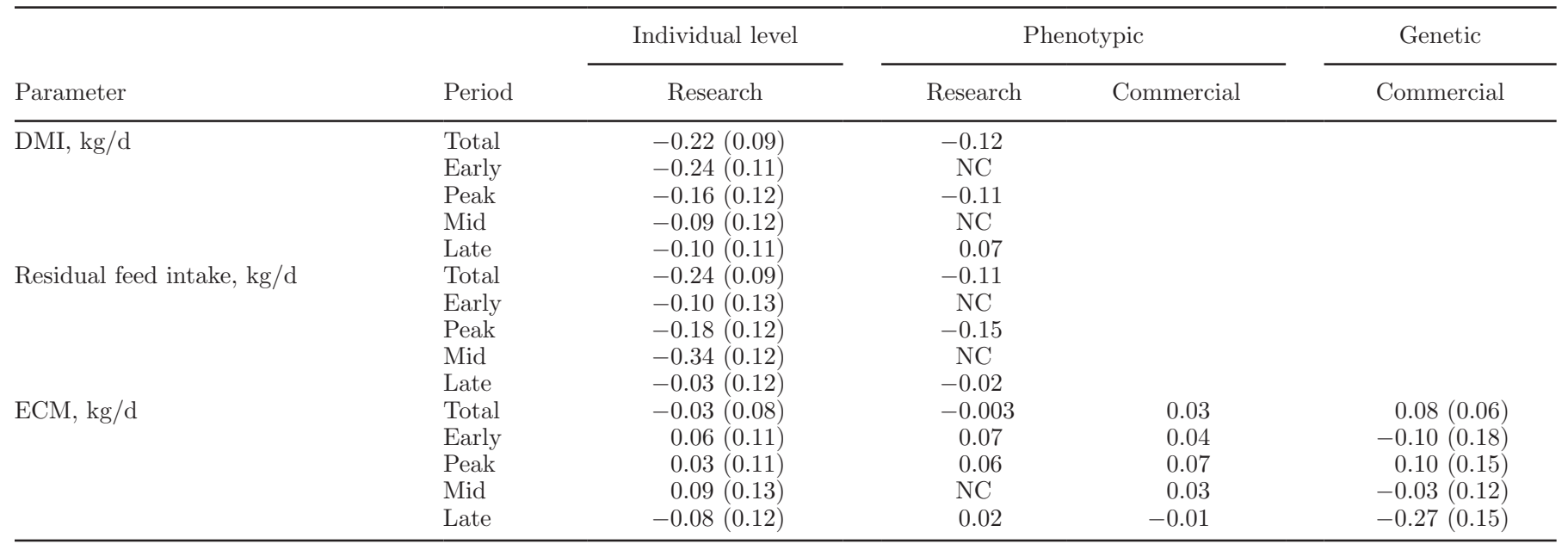

${ }^{1}$ Results are correlations with SE in parentheses; $\mathrm{NC}=$ not converged. 
Table 4. Individual level correlations (research herds) and genetic correlations (commercial herds) within traits between lactation periods ${ }^{1}$

\begin{tabular}{|c|c|c|c|c|}
\hline Parameter & Period & Peak & Mid & Late \\
\hline \multicolumn{5}{|l|}{ Research herds } \\
\hline \multirow[t]{3}{*}{$\mathrm{DMI}, \mathrm{kg} / \mathrm{d}$} & Early & \multirow[t]{3}{*}{$0.92(0.05)$} & $0.70(0.10)$ & $0.71(0.10)$ \\
\hline & Peak & & $0.81(0.07)$ & $0.78(0.08)$ \\
\hline & Mid & & & $0.95(0.03)$ \\
\hline \multirow[t]{3}{*}{ Residual feed intake, $\mathrm{kg} / \mathrm{d}$} & Early & \multirow[t]{3}{*}{$0.85(0.08)$} & $0.13(0.20)$ & $0.09(0.20)$ \\
\hline & Peak & & $0.59(0.15)$ & $0.36(0.20)$ \\
\hline & Mid & & & $\mathrm{NC}$ \\
\hline \multirow[t]{3}{*}{ Rumination time, $\min / \mathrm{d}$} & Early & \multirow[t]{3}{*}{$0.86(0.03)$} & $0.69(0.06)$ & $0.54(0.09)$ \\
\hline & Peak & & $0.86(0.03)$ & $0.67(0.07)$ \\
\hline & Mid & & & $0.78(0.04)$ \\
\hline \multirow{3}{*}{$\mathrm{ECM}, \mathrm{kg} / \mathrm{d}$} & Early & \multirow{3}{*}{$0.93(0.04)$} & $0.82(0.06)$ & $0.63(0.09)$ \\
\hline & Peak & & $0.95(0.03)$ & $0.89(0.04)$ \\
\hline & Mid & & & $0.96(0.02)$ \\
\hline \multicolumn{5}{|l|}{ Commercial herds } \\
\hline \multirow[t]{3}{*}{ Rumination time, $\min / \mathrm{d}$} & Early & \multirow{3}{*}{$0.97(0.01)$} & $0.95(0.02)$ & $0.92(0.03)$ \\
\hline & Peak & & $\mathrm{NC}$ & $0.97(0.02)$ \\
\hline & Mid & & & $\mathrm{NC}$ \\
\hline
\end{tabular}

${ }^{1}$ Results are correlation coefficients with $\mathrm{SE}$ in parentheses; $\mathrm{NC}=$ not converged.

the trait in another stage. For the research herd, these correlations were estimated on the level of individual cows (Table 4). Dry matter intake correlated most strongly between mid and late lactation (0.95). As expected, the correlations weakened the further apart the periods were, but remained robust and positive regardless. The results are generally similar to previous findings (Koenen and Veerkamp, 1998; Veerkamp and Thompson, 1999; Hüttmann et al., 2009; Tetens et al., 2014), except that in those prior studies, the lactation period continued for only a maximum of 180 DIM.

For RT, the correlation between periods within the lactation were calculated as individual level correlations for the research herd and as genetic correlations for the commercial herds. For the research herd, strong correlations were found between early and peak lactation and between peak and mid lactation (0.86). For commercial herds, strong correlations were also found between early and peak lactation and between peak and mid lactation (0.97). For both the research herd and commercial herds, the correlations weakened with increasing separation between periods. However, the correlations remained positive and robust, suggesting that the genetic background affecting RT remains consistent throughout lactation and that RT recorded at any random period during lactation reflects genetic influences on RT in general.

\section{Rumination Time in Research Versus Practical Environment}

Estimation of genetic parameters based on data from research facilities is limited by the limited size of data sets, which results in large standard errors and, consequently, uncertain reliability. Collection of data from commercial herds may provide an opportunity to examine how well genetic parameters under practical conditions correspond with those for research facilities. In general, we found that mean RT, repeatability, heritability, and correlations between periods within lactation were rather similar between the research herd and commercial herds. This gives reason to believe that estimates of genetic correlations between DMI and RT shows the same results; namely, RT is not a suitable indicator of DMI.

\section{CONCLUSIONS}

In conclusion, RT was found to be a highly repeatable trait with intermediate heritability in both experimental and commercial herd environments. The expectation of positive genetic correlation between RT and DMI was not supported by our data or estimates of individual level correlations. The RFI correlations were weak but favorable, with high RT related to high feed efficiency. Weak correlations between milk yield and RT were observed in both settings. Our findings indicate that RT is not a suitable indicator trait for feed intake and only a weak indicator of feed efficiency.

\section{ACKNOWLEDGMENTS}

This work was supported by a grant from the Danish Milk Levy foundation (Viby, Denmark; Nordic Feed Efficiency). The authors are grateful to personnel at the Danish Cattle Research Centre, Foulum, Denmark, for careful attendance to animals, and careful recording of data, and for careful handling of data special thanks 
to Connie Haarbo Middelhede and Martin Bjerring, Department of Animal Science, Aarhus University, Foulum, Denmark.

\section{REFERENCES}

Adin, G., R. Solomon, M. Nikbachat, A. Zenou, E. Yosef, A. Brosh, A. Shabtay, S. J. Mabjeesh, I. Halachmi, and J. Miron. 2009. Effect of feeding cows in early lactation with diets differing in roughageneutral detergent fiber content on intake behavior, rumination and milk production. J. Dairy Sci. 92:3364-3373.

Berry, D. P., M. P. Coffey, J. E. Pryce, Y. de Haas, P. Løvendahl, N. Krattenmacher, J. J. Crowley, Z. Wang, D. Spurlock, K. Weigel, K. Macdonald, and R. F. Veerkamp. 2014. International genetic evaluations for feed intake in dairy cattle through the collection of data from multiple sources. J. Dairy Sci. 97:3894-3905.

Berry, D. P., B. Horan, M. O'Donovan, F. Buckley, E. Kennedy, M. McEvoy, and P. Dillon. 2007. Genetics of grass dry matter intake, energy balance, and digestibility in grazing Irish dairy cows. J. Dairy Sci. 90:4835-4845.

Bikker, J. P., H. van Laar, P. Rump, J. Doorenbos, K. van Meurs, G. M. Griffioen, and J. Dijkstra. 2014. Technical note: Evaluation of an ear-attached movement sensor to record cow feeding behavior and activity. J. Dairy Sci. 97:2974-2979.

Braun, U., L. Trösch, F. Nydegger, and M. Hässig. 2013. Evaluation of eating and rumination behavior in cows using a noseband pressure sensor. BMC Vet. Res. 9:164.

Byskov, M. V., E. Nadeau, B. E. O. Johansson, and P. Nørgaard. 2015 Variations in automatically recorded rumination time as explained by variations in intake of dietary fractions and milk production and between-cow variation. J. Dairy Sci. 98:3926-3937.

Clément, P., R. Guatteo, L. Delaby, B. Rouillé, A. Chanvallon, J. M. Philipot, and N. Bareille. 2014. Short communication: Added value of rumination time for the prediction of dry matter intake in lactating dairy cows. J. Dairy Sci. 97:6531-6535.

Connor, E. E., J. L. Hutchison, H. D. Norman, K. M. Olson, C. P. Van Tassell, J. M. Leith, and R. L. Baldwin VI. 2013. Use of residual feed intake in Holsteins during early lactation shows potential to improve feed efficiency through genetic selection. J. Anim. Sci. 91:3978-3988

European Commission. 2015. EU Agricultural and Farm Economics Briefs. No. 7. EU Milk Marked Estimate up to 2014. An overview of estimates of costs of production and gross margins of milk production in the EU. Accessed May 20, 2016. http://ec.europa.eu/ agriculture/rica/pdf/Milk_margin_estimate_2014.pdf.

Gregorini, P., G. C. Waghorn, B. Kuhn-Sherlock, A. J. Romera, and K. A. Macdonald. 2015. Short communication: Grazing pattern of dairy cows that were selected for divergent residual feed intake as calves. J. Dairy Sci. 98:6486-6491.

Hüttmann, H., E. Stamer, W. Junge, G. Thaller, and E. Kalm. 2009 Analysis of feed intake and energy balance of high-yielding first lactating Holstein cows with fixed and random regression models. Animal 3:181-188.

Ingvartsen, K. L., and N. Friggens. 2005. To what extend do variabilities in hormones, metabolites and energy intake explain variability in milk yield? Domest. Anim. Endocrinol. 29:294-304.

Karacaören, B., F. Jaffrézic, and H. N. Kararmideen. 2006. Genetic parameters for functional traits in dairy cattle from daily random regression models. J. Dairy Sci. 89:791-798.

Koenen, E. P. C., and R. F. Veerkamp. 1998. Genetic covariance functions for live weight, condition score, and dry-matter intake measured at different lactation stages of Holstein Friesian heifers. Livest. Prod. Sci. 57:67-77.

Krause, K. M., D. K. Combs, and K. A. Beauchemin. 2002. Effects of forage particle size and grain fermentability in midlactation cows. II. Ruminal pH and chewing activity. J. Dairy Sci. 85:1947-1957.
Kristensen, T., C. Jensen, S. Østergaard, M. R. Weisbjerg, O. Aaes, and N. I. Nielsen. 2015. Feeding, production, and efficiency of Holstein-Friesian, Jersey and mixed-breed lactating dairy cows in commercial Danish herds. J. Dairy Sci. 98:263-274.

Li, B., W. F. Fikse, J. Lassen, M. H. Lidauer, P. Løvendahl, P. Mäntysaari, and B. Berglund. 2016. Genetic parameters for dry matter intake in primiparous Holstein, Nordic Red and Jersey cows in the first half of lactation. J. Dairy Sci. 99:7232-7239.

Liinamo, A.-E.. P. Mäntysaari, and E. A. Mäntysaari. 2012. Short communication: Genetic parameters for feed intake, production, and extent of negative energy balance in Nordic Red dairy cattle. J. Dairy Sci. 95:6788-6794.

Løvendahl, P., and M. G. G. Chagunda. 2011. Covariance among milking frequency, milk yield and milk composition from automatically milked cows. J. Dairy Sci. 94:5381-5392.

Madsen, P., and J. Jensen. 2010. Package for Analysing Multivariate Mixed Models. Version 6, release 5. Aarhus University, Research Centre Foulum, Tjele, Denmark.

Manzanilla Pech, C. I. V., R. F. Veerkamp, M. P. L. Calus, R. Zom, A. van Knegsel, J. E. Pryce, and Y. De Haas. 2014. Genetic parameters across lactation for feed intake, fat- and protein-corrected milk, and liveweight in first-parity Holstein cattle. J. Dairy Sci. 97:5851-5862.

Mertens, D. R. 1997. Creating a system for meeting the fiber requirements of dairy cows. J. Dairy Sci. 80:1463-1481.

Nørgaard, P., E. Nadeau, and A. T. Randby. 2010. A new Nordic evaluation system for diets fed to dairy cows: A meta analysis. Pages 112-120 in Modelling Nutrient Digestion and Utilisation in Farm Animals. D. Sauvant, J. Van Milgen, P. Faverdin, and N. Friggens, ed. Wageningen Academic Publishers, Wageningen, the Netherlands.

Schirmann, K., N. Chapinal, D. M. Weary, W. Heuwieser, and M. A. G. von Keyserlingk. 2012. Rumination and its relationship to feeding and lying behavior in Holstein dairy cows. J. Dairy Sci. 95:3212-3217.

Schirmann, K., M. A. G. von Keyserlingk, D. M. Weary, D. M. Veira, and W. Heuwieser. 2009. Technical note: Validation of a system for monitoring rumination in dairy cows. J. Dairy Sci. 92:6052-6055.

Tempelman, R. J., D. M. Spurlock, M. Coffey, R. F. Veerkamp, L. E. Armentano, K. A. Weigel, Y. de Haas, C. R. Staples, E. E. Connor, Y. Lu, and M. J. VandeHaar. 2015. Heterogeneity in genetic and nongenetic variation and energy sink relationships for residual feed intake across research stations and countries. J. Dairy Sci. 98:2013-2026

Tetens, J., G. Thaller, and N. Krattenmacher. 2014. Genetic and genomic dissection of dry matter intake at different stages in primiparous Holstein cows. J. Dairy Sci. 97:520-531.

Vallimont, J. E., C. D. Dechow, J. M. Daubert, M. W. Dekleva, J. W. Blum, C. M. Barlieb, W. Liu, G. A. Varga, A. J. Heinrichs, and C. R. Baumrucher. 2011. Short communication: Heritability of gross feed efficiency and associations with yield, intake, residual intake, body weight, and body condition score in 11 Pennsylvania tie stalls. J. Dairy Sci. 94:2108-2113.

VandeHaar, M. J. 1998. Efficiency of nutrient use and relationship to profitability on dairy farms. J. Dairy Sci. 81:272-282.

Veerkamp, R. F. 1998. Selection for economic efficiency of dairy cattle using information on live weight and feed intake: A review. J. Dairy Sci. 81:1109-1119.

Veerkamp, R. F., and R. Thompson. 1999. A covariance function for feed intake, live weight, and milk yield estimated using a random regression model. J. Dairy Sci. 82:1565-1573.

Williams, Y. J., J. E. Pryce, C. Grainger, W. J. Wales, N. Linden, M. Porker, and B. J. Hayes. 2011. Variation in residual feed intake in Holstein-Friesian dairy heifers in southern Australia. J. Dairy Sci. 94:4715-4725.

Yang, W. Z., and K. A. Beauchemin. 2007. Altering physically effective fiber intake through forage proportion and particle length. Chewing and ruminal pH. J. Dairy Sci. 90:2826-2838. 